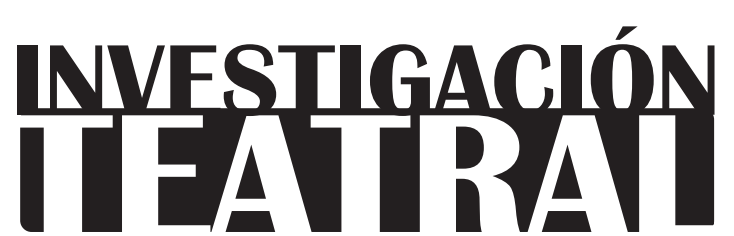

Revista de artes escénicas y performatividad

Vol. 11, Núm. 17

abril-septiembre 2020

Segunda época

ISSN impreso: 1665-8728

ISSN electrónico: 2594-0953

Universidad Veracruzana

\title{
Concepciones y especificidad del rol de la dirección teatral. Un caso en el teatro independiente argentino
}

\author{
Fwala-lo Marin*
}

\footnotetext{
* Consejo Nacional de Investigaciones Científicas y Técnicas. Centro de Investigaciones de la Facultad de Filosofía y Humanidades "María Saleme de Burnichón", Universidad Nacional de Córdoba, Argentina.

e-mail: fwalalomarin@gmail.com
}

Recibido: 19 de agosto 2019

Aceptado: 20 de marzo de 2020

Doi: $10.25009 /$ it.v11i17.2628 


\title{
Concepciones y especificidad del rol de la dirección teatral. Un caso en el teatro independiente argentino
}

\section{Resumen}

El rol de la dirección teatral es ostensiblemente inmaterial, lo que representa un desafío para el abordaje de su especificidad. Este trabajo analiza concepciones sobre dirección escénica en el teatro independiente de Córdoba, Argentina. Se abordan los conceptos que orientan sus prácticas directoriales, en el marco de una tradición centrada en el teatro de grupo. La investigación incluye entrevistas a directores cuyo discurso es analizado.

Palabras clave: teatro contemporáneo, director de teatro, discursos, trabajo de campo, teatro de grupo, Argentina.

\section{Conceptualizing the Role of the Theatre Director. A Case Study in Argentine Independent Theatre}

\begin{abstract}
The task of theatre directing is ostensibly immaterial, something that represents a challenge when analyzing its particular qualities. This article reviews topics that shape the concepts of "direction" and "theatre" in the independent theatre movement of Cordoba, Argentina. The concepts that guide director's practice are discussed, within the framework of a tradition centered on the collective nature of theatrical work. This research project includes a discourse analysis of interviews made to Argentine directors.
\end{abstract}

Keywords: Contemporary theatre, Theatre director, Discourse, Field research, Group Theatre, Argentina. 


\section{Concepciones y especificidad del rol de la dirección teatral. Un caso en el teatro independiente argentino}

$\mathrm{E}$ ste trabajo se propone dar cuenta de las concepciones teatrales en el marco del teatro independiente de la ciudad de Córdoba, Argentina, y específicamente de aquellos aspectos relevantes en el rol de la dirección. Dentro del campo del teatro independiente, hemos observado un "canon de multiplicidad" (Dubatti, El teatro argentino 74) en las producciones, en los modos de entender la dirección, el grupo, el público, la obra e, inclusive, en la definición de lo específicamente teatral.

Cada hacedor despliega estrategias distintas a las de los otros, produce obras únicas, describe la particularidad de su práctica. Esta denominación es utilizada por los artistas para designar a las personas que participan del mundo del arte (Becker 54) del teatro independiente, sin distinción de roles. Cada caso es único, indudablemente; por ello, nuestra investigación espera comprender la heterogeneidad en su complejidad y, a la vez, como parte de un proceso histórico. Nuestro objetivo es generar herramientas para entender cómo funciona el campo del teatro independiente: mapear un estado de las cosas, trazar senderos que habiliten una escucha de la singularidad en la vorágine de la multiplicidad. Nos apoyamos en la idea de "cartografía" (Dubatti, Qué políticas 21) para abordar nuestro análisis. El estudio donde se inscribe este trabajo plantea trazar mapas superpuestos: al mapa histórico-sociológico se le superpone el mapa de las concepciones teatrales. En este escrito esperamos presentar parte de este último mapa, relativo a uno de los directores que forman parte del estudio.

Este trabajo parte de una investigación más extensa, ${ }^{1}$ la cual estudia doce directores y directoras reconocidos, referentes en el campo del teatro independiente de la ciudad

1 Este trabajo se enmarca en el desarrollo de una beca interna doctoral del Consejo Nacional de Investigaciones Científicas y Técnicas de Argentina. 
de Córdoba. La selección se fundamentó en criterios de consagración y edad, quedando integrada por quienes habían recibido más de dos distinciones nacionales, provinciales o municipales en el periodo 2013-2016 y habían nacido entre 1975 y 1985. Los directores y directoras seleccionadas son: David Piccotto, Marcelo Arbach, Daniela Martín, Martín Gaetán, Rodrigo Cuesta, Luciano Delprato, Eugenia Hadandoniou, María Belén Pistone, María Palacios, Gonzalo Marull, Jazmín Sequeira y Maximiliano Gallo. El objetivo es comprender cuál es el concepto con que se opera en el campo y cómo se construye su definición legítima, mediante los discursos de ellos. ${ }^{2}$ Esperamos que al finalizar nuestra investigación estemos en condiciones de hacer oír la diversidad de voces, incluyendo un análisis de los momentos en que las posturas crean armonías y aquellos en que ocurren disonancias.

Nuestra atención está centrada en las concepciones teatrales. ${ }^{3}$ Llamamos concepciones teatrales a los sentidos que organizan las prácticas y la manera en que éstas articulan, de modos singulares, la relación entre la audiencia, el ensayo, la dirección y el teatro. A su vez, los valores que albergan modifican sensiblemente los objetivos de sus prácticas directoriales. Su importancia se debe a la singularidad del teatro independiente de la ciudad de Córdoba. Ancladas en una tradición de fuerte grupalidad y experimentación, y envueltas en condiciones de producción desfavorables, las concepciones de dirección cordobesas tensionan las definiciones de "director" que tenemos como referencia.

2 En otros trabajos hemos presentado conclusiones parciales sobre aspectos sociológicos (Marin, "La formación de directores de teatro independiente argentino: aprendizajes en una periferia de tramas eclécticas. El caso de la ciudad de Córdoba", 2019; Marin, "Los trabajadores del arte. El caso de los directores de teatro independiente en Córdoba", 2018.), históricos (Marin, "De puentes y orillas: festivales como vínculo del teatro de los setenta con el teatro de postdictadura en la trayectoria de directores de Córdoba, Argentina", 2019) y un avance sobre las concepciones dentro del grupo de directores estudiado (Marin, "Dirección Teatral: del mundo del pensamiento al universo de las relaciones de grupo. Reflexiones en torno los procesos de escenificación del Teatro Independiente de Córdoba", 2018; Marin, "Films escénicos: teatro de préstamos y de piraterías", 2018).

3 Aunque consideramos que el estudio de la recepción de las concepciones teatrales que analizamos es central para completar los estudios del teatro independiente, dicho objeto de análisis escapa a los alcances de nuestra investigación. Sin embargo, invitamos a consultar los trabajos de Paula Beauleiu sobre el tema, en especial "Estudio de caso: oferta y consumo en el teatro independiente de la ciudad de Córdoba". En el mismo sentido que en este trabajo, la autora demuestra que los "creadores se consideran a sí mismos como el espectador modelo, a la vez que no están dispuestos a hacer concesiones con el espectador real" (131), y logra caracterizar a los espectadores del teatro independiente mediante criterios educativos, económicos y etarios. 
Desde una perspectiva sociológica, Serge Proust define la dirección como un trabajo artístico que requiere calificaciones artísticas y juicios estéticos específicos:

Hay componentes materiales pre-existentes (la escenografía, el texto dramático, los cuerpos de los actores) que pueden producir juicios estéticos o técnicos. Pero el trabajo de artificación demanda un esfuerzo de categorizar y nombrar cosas, combinar y subsumir esos elementos a fin de constituir una realidad que es otra y se reconoce como "superior", y por esa razón se constituye como el principal foco de discusión (339). ${ }^{4}$

La dirección se vale del concepto de "artificación" (Heinich y Shapiro 20): un proceso de trabajo caracterizado por cruces entre lo artístico y lo no-artístico, que ocasionan un cambio de definición y estatus de las personas, los objetos y las actividades. Para Proust, el reconocimiento se obtiene mediante la creación de una nueva realidad inmaterial a partir de materiales existentes, donde los directores son artistas que gradualmente van distinguiéndose de otros participantes del proceso por la combinación de varios atributos: "la habilidad de unificar en la escena un número creciente de componentes (actuación, iluminación, escenografía, vestuario, sonido y más); la intelectualización de esa actividad mediante la producción de reflexiones, y la monopolización de recursos públicos" (339). ${ }^{5}$ La noción del autor está inscripta en las prácticas del teatro público parisino.

Desde otra perspectiva, Peter Boenisch, en Directing Scenes and Senses: The Thinking of Regie, considera las conceptualizaciones de Rancière respecto del "reparto de lo sensible" (9). Propone pensar a la dirección de un modo que supere la visión del director como propietario y última autoridad de la obra, controlando todos sus aspectos (8). La mediación es una noción relevante en su planteo:

¿Cuál es la mediación que la dirección realmente implica? Como medium, el teatro establece relaciones: por medio de su performance, relaciona el texto escrito con el

$4 \quad$ La traducción es nuestra: "There are of course pre-existing material components (the sets, the playwright's text, the actors' bodies, etc.), which can elicit technical and/or aesthetic judgements. But the work of artification demands an effort to categorize and name things, combining and subsuming these elements so as to constitute a reality that is other and recognized as 'superior', and which for that very reason becomes the main focus of discussion" (Proust 339).

5 La traducción es nuestra: "the ability to unify the staging of a growing number of components (the acting, lighting, sets and scenography, costumes, sound, and so on); the intellectualization of this activity through the production of commentary; and the monopolization of public resources" (Proust 339). 
momento presente, en el cual una audiencia expecta y siente el texto, mediado por la puesta en escena. [...] Como proceso de mediación, la dirección organiza las escenas, los sentidos ${ }^{6}$ y las percepciones que interconectan procesos de dirección (y performance) con actos de expectación (21-22). ${ }^{7}$

Cada una de estas dos propuestas nos sitúa en unas coordenadas particulares: por un lado, describiendo las prácticas directoriales como prácticas sociales, como un proceso de trabajo que implica habilidades y reconocimiento; por el otro, una revisión del concepto de dirección en función de la distribución del mundo sensible. Cabe aclarar que Rancière refiere a la "distribución y redistribución de los lugares y las identidades, de lo visible y lo invisible, del ruido y de la palabra" (34) como constitutivos de lo que denomina el reparto de lo sensible.

En el cruce de estas perspectivas realizaremos nuestra aproximación. Valiéndonos de las conclusiones de nuestras indagaciones anteriores, distinguimos cuatro tópicos que permiten aproximarnos al concepto: teatro, grupo, público y proceso de creación. Nos parece relevante considerar la relación entre ellos: la dirección interviene de algún modo en la producción de una obra de teatro (modo que comprenderemos mediante el análisis), generada por un grupo, que se presentará ante un público y que, en virtud de este proceso de creación y del vínculo entre la audiencia y el grupo, se constituye una determinada noción de teatro como un acontecimiento "convivial-poético-expectatorial" (Dubatti, Introducción 30). Por ello, abordaremos, además de los sentidos que aparecen en la definición de grupo, los sentidos pertinentes a la noción de público y de teatro. Sin embargo, consideraremos centralmente el concepto de dirección en función de las definiciones que ofrece el caso de estudio. Este enfoque nos permite dilucidar los sentidos construidos en torno al rol de la dirección, especialmente en un miembro que sintetiza los valores y concepciones que hegemonizan en buena medida la definición legítima para el campo.

Mediante una propuesta de análisis discursivo y análisis narrativo, se abordará el caso de uno de los directores que pueden ser considerados referentes del teatro independiente de Córdoba. El marco metodológico propuesto obedece a "una estrategia para hacer que la

6 Senses puede comprenderse como sentidos, sensaciones, percepciones o sentimientos.

7 La traducción es nuestra: "So, what does this mediation of Regie actually entail? As a medium, theatre establishes relations: via its production and performance, it relates the written playtext with the present moment, in which an audience sees and senses the playtext, mediated through the production [...] As a process of mediation, Regie organises the scenes and senses that interconnect processes of directing (and performing) with acts of spectating" (Boenisch 21-22). 
gente hable sobre lo que sabe, piensa y cree" (Guber 69). Se realizaron entrevistas etnográficas, ya que consideramos que:

[...] es una situación cara a cara donde se encuentran distintas reflexividades pero, también, donde se produce una nueva reflexividad. La entrevista es, entonces, una relación social a través de la cual se obtienen enunciados y verbalizaciones en una instancia de observación directa y de participación (70).

El material obtenido es relevante en cuanto genera un documento sobre una práctica que se encuentra escasamente registrada, al menos al nivel de las metodologías de creación o trayectorias formativas. Una vez realizada la entrevista, contamos con el texto verbal transcripto y la posibilidad de volver a un registro audiovisual del encuentro. El diseño del análisis fue producto de varios movimientos. Retomamos algunas preguntas de Aguilar y otros respecto al tratamiento de los discursos sociales: ¿Cómo interpelarlos sin producir los resultados descriptivos tan habituales en las ciencias sociales? ¿Cómo ir "más allá" de las críticas a la referencialidad del lenguaje, a su transparencia supuesta, al objetivismo y empirismo científicos desde el marco que nos proveen las ciencias sociales? ("El análisis de los discursos sociales" 1 ).

Mediante aproximaciones de este tipo, arribamos a una textualidad extensa, descriptiva y minuciosa sobre los tópicos escogidos. Sin embargo, esto presentaba aún más dificultades a nuestro propósito comparativo, que requería operaciones de síntesis. Era necesario construir ejes transversales que pudieran organizar la diversidad y enunciados sintéticos que pudieran condensar las concepciones teatrales. Este tipo de operaciones precisaba de manera obligatoria una aproximación cuidadosa que no fuese más allá de lo dicho, sin involucrar aquello que conocíamos a través de la obra del entrevistado o del conocimiento de su pedagogía. Esta restricción se fundó en que el ámbito de nuestro análisis está circunscripto a la "metapoética" de los y las directoras (Dubatti, Introducción 128), y no a la observación de los ensayos de cada uno de ellos y ellas, ni al estudio de sus obras. ${ }^{8}$ Del mismo modo, a lo largo de la entrevista se aludía a temas relevantes que fueron presentándose de manera indirecta y, en menor medida, de forma directa. Inclusive, cuando alguna pregunta volvía a versar sobre alguno de los temas, las respuestas presentaban un contenido levemente diferente entre una interlocución u otra, o directamente contradictorio.

8 Debido a que no todos los directores y directoras se encontraban en procesos de ensayo o de presentación de obra, o bien, porque lo que estaban ensayando pertenecía al ámbito oficial o comercial, que no forman parte de nuestro estudio, ya que son condiciones de producción diferentes. 
La metodología, además, debía considerar la proximidad de quien investiga y del director entrevistado: ambos pertenecen al ámbito del estudio universitario del teatro y de la producción de obra en el marco del teatro independiente. Esta situación ofrecía ventajas como, por ejemplo, durante la entrevista, la posibilidad de una comprensión mutua, de preguntas y respuestas, ya que el contexto de la comunicación era compartido. Apoyándonos primero en herramientas del campo de la etnografía, valoramos la interpretación de las "pistas meta-discursivas" como fundamental para comprender el sentido de lo dicho (Pizarro 463), reconociendo tanto la indexicalidad del lenguaje como su reflexividad para orientar nuestra tarea de investigación (Guber 44).

De este modo, optamos por el "análisis del discurso" (Verón; Calsamiglia Blancafort y Tusón Valls; Charaudeau y Maingueneau) que nos permitió realizar una "lectura" de las concepciones teatrales que contenía la entrevista. Una de las herramientas fundamentales fue la elaboración de "semas", entendiendo su "naturaleza relacional y no sustancial", que no puede "sino definirse como término-resultado de una relación instaurada y/o aprehendida con, al menos, otro término de una misma red relacional" (Greimas, Semiótica estructural 349).

Las categorías semánticas que construimos fueron parte del trabajo de análisis de la entrevista, extrayendo de los dichos de la persona entrevistada aquellos tópicos relevantes a nuestros propósitos. Al mismo tiempo, con el objeto de sintetizar las concepciones, tomamos el concepto de isotopía, definido por Greimas como "un conjunto redundante de categorías semánticas que hace posible una lectura uniforme del relato" (Semántica 222).

Estos conceptos, junto con otros provenientes del análisis "narratológico" (Bertrand 181), serán las herramientas de análisis de una metodología híbrida que busca "ir más allá de lo que se dice, de lo que queda en la superficie de las evidencias discursivas" (Orlandi 18). En el mismo sentido, comprendemos que "un discurso trae consigo una memoria" y una filiación de decires que nos permiten reconocer en él "los efectos de sentido que se hacen presentes, aun sin el control absoluto del sujeto que dice" (20). Por ello, fundamentalmente, se consideraron los deícticos diseminados en la trama discursiva de la entrevista, que permiten dar cuenta del acto de enunciación, del tiempo, el espacio y los actantantes que participan del "discurso" (Benveniste 14, Kerbrat-Orecchioni 73).

En la entrevista realizada a cada director o directora ${ }^{9}$ referente del teatro independiente de Córdoba sobre la dirección teatral, se extrajeron aquellos pasajes que atienden a los tópicos: concepto de dirección, prácticas de la dirección, concepto de grupo, concepto de público, singularidad poética, definición de lo específicamente teatral. Resguardamos sus

9 A lo largo del documento hemos designado al sujeto de la entrevista como "el director", pero consideramos que hubiera sido adecuado el uso del lenguaje inclusivo habilitando el género neutro. 
nombres, ya que la relevancia radica en conocer las concepciones que operan en el "campo" (Bourdieu 309, 320) y no la titularidad de las mismas. Nos adherimos a la compresión de "posiciones" (341) y no de la descripción de las poéticas de sujetos concretos, al menos en este trabajo.

Lo anterior se dice entendiendo que el campo del teatro independiente puede ser concebido como una red de relaciones entre posiciones y que cada posición es definida por su relación con las demás, cada una de ellas ostentando una determinada estructura de especies de capital, como parte de un juego por una "ilusio" (340). A continuación, presentamos nuestra propuesta de análisis discursivo, atendiendo a las huellas que recogemos de la entrevista.

\section{Enunciaciones sobre la dirección teatral}

En primer lugar, el estudio de los deícticos nos brindó las claves para el abordaje del discurso. Entendiendo que varían de situación a situación, dan cuenta de "la especificidad de su funcionamiento semántico-referencial" cuando se toman en consideración "los parámetros constitutivos de la situación de enunciación" (Kerbrat-Orecchioni 45), con éstos nos referimos al papel que desempeñan los sujetos "del enunciado en el proceso de la enunciación" y a "la situación espacio-temporal del locutor y del alocutario" (48). Los deícticos que analizamos fueron: pronombres personales, la localización temporal del sujeto de enunciación y la localización espacial.

Atendiendo al tiempo de la enunciación, se manifiesta el tiempo de la acción "dirigir" y el relato alrededor de su conceptualización por parte del director, en algunas frases con el deíctico "acá", acompañado de verbos en presente para hacer referencia al proceso teatral. De esta forma establecemos como momento cero de la enunciación el propio proceso teatral, que se presenta como el aquí-ahora del relato:

[...] yo, como la persona que dirige, qué estrategias desarrollo para que las condiciones estén dadas, para que las condiciones para que se desarrolle una inteligencia colectiva estén dadas [...] Es llamar la atención para que 'ey, pensemos que está pasando acá, qué está pasando con esto.' [...] 'veamos qué está pasando, acá hay un problema dramatúrgico en este sentido, cómo piensan que podemos resolverlo’ [cursivas añadidas] (Director, entrevista).

El director se sitúa desde un presente de práctica escénica para presentar sus enunciados. En este ejemplo, también implica consideraciones acerca del espacio: el deíctico "acá" planea 
el lugar desde donde se habla a un sitio habitado y cercano. "Acá" es el teatro, versus un allá que es el no-teatro. Además de este punto, fueron nombradas otras formas espaciales como "adentro-afuera" de la escena, o bien "la escena / este lado" para referirse al sitio del director: "yo específicamente [era] el que estaba tratando de colaborar desde afuera con que se potencien las actuaciones, las escenas, y ellos hacían lo suyo desde adentro" o "desde adentro lo viviste así, yo desde afuera lo viví asá" (Director, entrevista).

Entonces, afirmamos que el espacio de la enunciación se sitúa en la situación escénica, donde unos están dentro y el director, fuera. La particularidad de esta ubicación espacial se puntualiza al hablar de la percepción del ritmo de una escena, la potenciación de las actuaciones, las percepciones individuales sobre la construcción escénica. Es importante considerar que, al establecer el lugar de la enunciación en el marco de una situación escénica -es decir, el ensayo en la intimidad del proceso creativo de un grupo-, el adentro y el afuera quedan circunscriptos a ese marco. En el mundo de afuera de la escena, sólo se encuentran el director y los técnicos en sonido o luz, no así los espectadores u otros agentes del mundo social.

De esta organización espacial del relato surgen los sujetos, ${ }^{10}$ el director y los actores. Surgen otros: por un lado, "todos y todas" que refiere al grupo teatral que realiza obras de teatro, al igual que la voz "cada uno": "Eso lo hacíamos todos y todas. Porque en realidad cada uno, yo no era el único que llevaba propuestas [al ensayo]"; "[un proyecto] tiene que ver con partir de lo que cada uno, como que de las heridas abiertas o esos lugares de, en donde a cada uno algo les mueve, algo te mueve" (Director, entrevista). Es notable cómo esta voz se reitera en numerosas ocasiones en el texto para presentar el accionar del grupo que, pudiendo ser un sujeto colectivo, se presenta como sujetos individuales que mantienen los mismos objetos de valor y programas narrativos. El sujeto individual es, más claramente, "el director":

[...] ese ir y volver de la propuesta y recoger lo que surge de la propuesta, lo hicimos todos, no yo, exclusivamente, por ser la persona que dirige. Yo en el rol de director lo que hice más específicamente o diferente a ellos [...] yo dirigía más actoralmente lo que sucedía porque era el único que me quedaba de este lado (Director, entrevista).

Además de estos dos personajes, que se encuentran circunscriptos a la situación escénica, surgieron otros personajes. Uno de ellos fue "el espectador" y su ingreso en el discurso estuvo dado con motivo de referirse a las percepciones y experiencias que suscita la propuesta poética. A lo largo de la entrevista, el director utiliza distintas nominaciones

10 En la teoría greimasciana, el término sería "personaje"; sin embargo, optamos por esta otra denominación para evitar confusiones. 
para aludir a este concepto general. Las palabras adscriben a sentidos distintos (Orlandi 13) y fueron empleadas para construir situaciones de enunciación diferentes. De modo más general, se designó "el público" ("una obra que va a salir a dialogar con el público de determinada manera") a la nominación más genérica respecto de la otredad que se presenta en la relación teatral (Director, entrevista). En el mismo orden, se refiere a ellos como "ésos que están ahí" y "ésos que vinieron a esa función" (Director, entrevista). El deíctico "ésos" marca una relación con la segunda persona (tú), a diferencia de "éstos", que está asociado a la primera persona, o "aquéllos" a la tercera. "Ésos" también establece relaciones espaciales: "allá" versus "acá" o "ahí" versus "allí". El deíctico marca una distancia prudente entre el sujeto enunciador y los espectadores, del mismo modo que lo hace "ahí": los espectadores no están próximos a la dirección, ni en el mismo espacio ni en el mismo tiempo, ya que "esa función" es un momento que ocurre a una distancia temporal con el tiempo cero de la enunciación, que es el ensayo.

A su vez, plantea que el concepto encierra complejidades: "cierta prudencia de no intentar creer que uno puede llegar a descubrir cómo va a llegar a recibir mi espectáculo el público" (Director, entrevista), para luego arribar al concepto "públicos determinados": "soy consciente de que hay lugares que van a traer, en términos generales, a públicos determinados con determinadas características" (Director, entrevista). Para referirse al público que asiste a las funciones de teatro independiente en el marco de la sala en la que presenta sus espectáculos, dichas características, que describen "franjas", son:

- "Quienes van más por el entretenimiento" (Director, entrevista): se describe a quienes participan de la actividad teatral con fines recreativos. Sin embargo, es un tipo de recreación selecta, ya que el teatro independiente es un arte de acceso restringido, no por su precio, sino por la escasa información circulante. Ésta está disponible, principalmente, entre círculos intelectuales o artísticos. Hay una búsqueda de goce estético.

- "Otros, porque reconocen que está el capital cultural ahí, como el leer una buena novela, bueno, a ver ir a ver una buena obra de teatro que te dijeron que está buena" (Director, entrevista): se reconoce que un grupo de espectadores participa de la actividad en función de un criterio de calidad, de un juicio previo hecho por un espectador anterior en el que confía como referencia. Hay una búsqueda de goce estético, también, entre los espectadores de esta franja.

- "Otro grupo que irá para decir que pertenece a un círculo que le aporta un bien cultural, aunque quizá no necesariamente lo disfrute, pero le aporta en términos simbólicos, algo, pertenecer a un grupo" (Director, entrevista): se distingue que el principal objetivo de los espectadores no es el goce estético, sino la identificación en un círculo social. 
- "La gran franja que está en formación o que le interesa también como forma de vida, como aprendizaje, la gente que está haciendo" (Director, entrevista): este grupo reúne a aquellos interesados en la actividad teatral como camino profesional y que se configuran como espectadores con fines formativos.

Se presenta otro grupo de espectadores que quedan por fuera de los mencionados antes, es decir, no participan de los espacios de distribución del teatro independiente y sobre los que marcan distancia. Ese otro grupo es mencionado a la vez que se introduce otro sujeto, "las instituciones":

Creo que [en] las instituciones, hay algo de cierta vocación clientelista también, de que, bueno, que tienen la idea de que el teatro, como expresión artística, tiene que ser para muchos; hay ciertos como lugares, para mí, del sentido, como sobreentendidos comunes que la institución, las instituciones adscriben, que tienen que ver con esto, con que, bueno, buscar manifestaciones más populares, que llegue más masivamente a todos, a todas las familias. El teatro que yo hago, justamente, va en contra; sería como el enemigo de eso (Director, entrevista).

Tanto "las instituciones" como "las familias" son sujetos colectivos y, a la vez, a cada uno se le pueden asignar características por sus roles temáticos. Con este término nos referimos "al conjunto de acciones socialmente definidas que se atribuyen a un personaje" (Triquell 59). En función de esto, las instituciones son agentes que en buena medida controlan las reglas de juego del campo del arte y los recursos. Suponen velar por un bien común, especialmente las que son parte de la esfera estatal. En este sentido, cuando se les atribuye la característica "clientelista", ésta entraría en conflicto con el bien común. Estarían asociadas a beneficiar a determinado grupo con el fin de obtener y mantener el poder, asegurándole fidelidades a cambio de favores y servicios.

Por su parte, las familias son agentes que incluirían niños y adultos, que conjuntamente asisten a un espectáculo con fines recreativos para realizar una actividad de entretenimiento que convoca a los niños por excelencia. A partir de la frase "Narrativas más convencionales, [...] hay una temática, hay una historia, personajes que son más o menos reconocibles" (Director, entrevista), podemos reconocer el contenido de las narrativas convencionales: personajes, historia y tema reconocibles.

De las caracterizaciones de los sujetos obtenemos una serie de oposiciones y enunciados: por un lado, los espectadores de teatro independiente y, por otro, las familias e instituciones orientadas por concepciones de teatro diferentes. 
Tabla 1

\begin{tabular}{|l|l|}
\hline \multicolumn{2}{|c|}{$\begin{array}{r}\text { Reparto de los espectadores en función de los espacios } \\
\text { y el concepto de teatro que los orienta }\end{array}$} \\
\hline $\begin{array}{l}\text { Los espectadores de las salas de teatro independiente } \\
\text { y del teatro que allí realiza el director y cada uno de los } \\
\text { miembros del grupo: }\end{array}$ & $\begin{array}{l}\text { Las familias y las instituciones: } \\
\text { - Orientadas por un concepto de teatro como } \\
\text { arte masivo, popular, ligado a narrativas } \\
\text { convencionales. }\end{array}$ \\
$\begin{array}{l}\text { Orientados por un concepto de teatro que altera } \\
\text { las lógicas convencionales, que se opone al teatro } \\
\text { masivo y popular. }\end{array}$ & \\
\hline
\end{tabular}

Nota: Las columnas se plantean como oposiciones.

Hasta aquí realizamos el análisis discursivo, que incluyó reconocer cuáles eran el espacio, el tiempo y los personajes de la entrevista para, después, realizar una lectura significativa de estos aspectos. Lo que continúa es el tratamiento del discurso al nivel narrativo.

\section{Un análisis narrativo de la dirección teatral}

Profundizando en el análisis, revisamos nociones narratológicas con el objeto de establecer la naturaleza de los roles, complejizando la comprensión habitual de las funciones de los distintos miembros de un grupo teatral. Decidimos problematizar dichos roles desde esta perspectiva con el objeto de presentar otras relaciones distintas a las que habitualmente suelen definirse en el campo. Nos referimos a la idea de que un grupo produce una obra teatral, luego de un proceso que, finalmente, dará lugar a funciones a público. Esta frase sintetizaría el quehacer teatral independiente; sin embargo, es necesario aún establecer cuáles son los valores, las funciones de cada actante y los deberes, ser y hacer de cada quien. La estructura actancial del discurso permite ir más allá de los sujetos para observar las funciones de los actantes, que son construidos teóricamente. Nos apoyaremos en categorías de la síntesis actancial, esperando establecer "la estructura elemental de la acción" (Bertrand 183). Hablamos, entonces, de "objeto de valor"; del "programa narrativo", es decir, de la transformación que se espera generar en el proceso; del sujeto que sufre la transformación o "sujeto de estado"; del sujeto que lleva adelante la transformación o "sujeto de hacer", y, por último, del sujeto que le hace hacer al sujeto de hacer designado como "destinador". En el nivel de análisis actancial, constituyen actantes "El director" (D), "Cada uno de los miembros del grupo" (G) y "El espectador" (E).

Se constituyen como valor de "la singularidad", base del poder hacer-hacer, "la poética propia", "la inteligencia colectiva" (una competencia o saber-hacer) y "la obra" (es el resultado del proceso), que establecemos de pasajes de la entrevista: 
Coordinar el proceso grupal para asegurarme que se den las condiciones necesarias para que se geste esa inteligencia colectiva. [...] Coordinar un grupo de trabajo, grupo de trabajo que tiene que construir sus propias reglas de producción, que tiene que tener una autonomía, que tiene que salir a buscar, descubrir y hacerse cargo de una poética (Director, entrevista).

El grupo y el director desean entrar en conjunción con estos objetos. Particularmente, el director desea alejarse de los antivalores, que serían "el autoritarismo" y "la homogeneización":

No reemplazaría la palabra dirección por coordinación [...] como si ser director fuera medio pecaminoso porque sos una figura de autoridad, verticalista [...] me parece que está bueno decir que acá hay un rol que por ahora le sigamos llamando dirección, el tema es refundar el sentido o abrirlo al sentido, que no necesariamente dirigir sea lo que históricamente se entendió como dirigir, la cuestión verticalista del poder. La dirección tiene una de sus funciones claves [...] llegar a ver cómo se complementan los puntos de vista diferentes, heterogéneos, singulares, no perder de vista la singularidad en lo colectivo, no homogeneizar (Director, entrevista).

Tomaremos en cuenta, para analizar los pasajes, las categorías "sujetos de estado" y "sujetos de hacer". Los primeros son aquellos que sufren la transformación: de pasar a estar en disyunción con los objetos de valor, a estar en conjunción con éstos. En este caso, además, se constituyen, al mismo tiempo, en sujetos de hacer. Es decir, llevan adelante el programa narrativo. Esto da cuenta de que son objetos modales, del orden de la competencia, en tanto habilitan este paso del sujeto de estado a sujeto de hacer. "Cada uno de los miembros del grupo", incluyendo en este caso al director, en un primer momento se encuentra en disyunción con la obra, con la inteligencia colectiva, con la poética propia y con la singularidad. En un segundo momento, luego de haber desarrollado una metodología de creación, entran en conjunción con estos objetos. Las acciones que el sujeto-de-hacer "grupo" llevó adelante fueron "llevar propuestas, ir y volver de la propuesta y recoger lo que surge de la propuesta", "cuando ya teníamos la obra y ya entre todos pensamos el montaje de las escenas", "entre todos escribimos la dramaturgia"; lo que específicamente llevó adelante el director, como sujeto de hacer, fue "dirigía más actoralmente lo que sucedía" (Director, entrevista).

Resta preguntarse cuál es el agente que estaría ocupando el lugar del destinador, quien hace hacer: "al entrar en relación con el destinatario que, al aceptar su mandato, se convierte

$11 \quad$ Ver cita extensa en la página 86. 
INVESTIGACIÓNTEATRAL

Revista de artes escénicas y performatividad

Vol. 11, Núm. 17

abril-septiembre 2020
Concepciones y especificidad del rol de la

dirección teatral

Fwala-lo Marin

en sujeto de hacer y opera la transformación" (Triquell 61). Nos detenemos en la cualidad distintiva de la dirección, descrita como la capacidad de "coordinar el proceso grupal para asegurarme que se den las condiciones necesarias para que se geste esa inteligencia colectiva. Eso sí siento que fue lo más, más específico en mi rol”. En otro pasaje aclara:

[...] para mí la dirección [...] Es como un rol de habilitación de potencias colectivas que deviene en obra poética. Tiene mucho que ver con habilitar el encuentro y habilitar teniendo presente, como los deseos que arrastran potencias y que contagian, que permiten circular y amplificar y multiplicar lo que podemos (Director, entrevista).

En tanto realiza una "habilitación de potencias colectivas", implicaría un trabajo sobre las competencias del otro, específicamente del saber y el poder hacer. De este modo, consideramos que la especificidad del rol se sintetiza en la construcción de las condiciones para llevar adelante la metodología de creación y lograr arribar, mediante la inteligencia colectiva, a la obra de poética singular. Según los esquemas de análisis que adoptamos de Bertrand (184) podemos afirmar lo siguiente.

\section{Figura 1}

\footnotetext{
$\mathrm{D}$ Director

PN:condiciones para

llevar adelante la

metodología de

creación

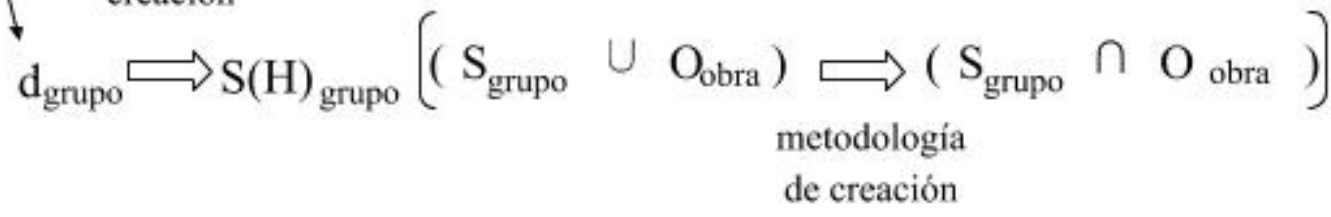

"D" es destinador

"d" destinatario

"S" sujeto de estado

"U" disyunción

"PN" programa narrativo "S $(\mathrm{H})$ " sujeto de hacer "O" objeto de valor " $\cap$ " conjunción

Figura 1: El Destinador "Director" destina el programa narrativo ("las condiciones para llevar adelante la metodología de creación") al destinatario "grupo" para que éste se constituya en sujeto de hacer y realice las transformaciones; al llevar a cabo la metodología de creación, pasará de estar en disyunción con el objeto "obra" a estar en conjunción con él.
} 
Si el director es quien garantiza las condiciones para que se produzca la metodología de creación, asigna al grupo un programa narrativo, un deber hacer, un programa narrativo: es, por tanto, el destinador. Por ser también un miembro del grupo, asume del mismo modo la metodología y hace junto con los demás, entrando en conjunción con la obra; en esa otra situación, se integra al actante grupo como sujeto de hacer y sujeto de estado. Es relevante considerar cómo en otros pasajes de la entrevista el espectador se constituye como sujeto de estado que entraría en conjunción con la obra, una vez vivenciada la experiencia teatral. Hasta aquí, establecimos funciones actanciales y realizamos lecturas propias de este nivel de análisis. El siguiente apartado indaga en el "nivel sémico", es decir, de mayor abstracción y profundidad en relación a la superficie textual.

\section{Para una lectura de las concepciones teatrales}

Como presentamos anteriormente, el diseño metodológico espera producir una condensación de las concepciones teatrales con las que opera el rol de la dirección. Por ello, optamos por establecer isotopías a lo largo de la entrevista. Luego del análisis formulamos una serie de enunciados de la entrevista, que podemos agrupar en función de tres ejes: las metodologías de creación, el resultado de esta última y su recepción. En la siguiente sección se presentarán pasajes de la entrevista y los tópicos que elaboramos a partir de ésta. Más adelante se reúnen dichos tópicos en una tabla que condensa los ejes trabajados. Mediante este tratamiento, nos acercamos al establecimiento de los semas y sus pares isotópicos. De pasajes que hemos citado anteriormente (cita extensa en la página 91) extraemos los tópicos: dirección como coordinación (a) y autoridad verticalista (b). Del siguiente fragmento, pasamos en limpio: la importancia de la metodología de creación (c) y, por otra parte, búsqueda del autoconocimiento personal $(\mathrm{d})$ :

[...] fuimos indagando en una metodología que es supercolectiva, en el sentido de que hay una escena a la que se arribó porque pasó por las múltiples resonancias de todos [...] partir de lo que cada uno, como que de las heridas abiertas [...] te estás abriendo a auto-conocerte y a indagar más en vos, eso también es como una fuerza de contagio a otro, como una invitación a ir en profundo, en algo que sea significativo para mí (Director, entrevista).

Atendiendo al siguiente pasaje, sintetizamos los tópicos: atención sobre el proceso, experimentación, reflexión (e): 
[...] a pensar el teatro [...] que no es sólo un oficio o una práctica que está localizada en los ensayos, en el cuerpo, en el hacer, sino también una práctica que se nutre de hacerse preguntas, de leer, de cuestionar, de pensar, de organizar encuentros con otras personas. [...] pensar el teatro más dentro del campo teatral específico, los ensayos, lo que es la dramaturgia de la escena, la dramaturgia de la actriz, del actor (Director, entrevista).

De otro pasaje deducimos: el proyecto emerge de los deseos personales (f) y, por contraposición a lo que plantea el director en la cita, proyecto que emerge de una idea previa, de un lugar adonde arribar (g):

[un proyecto] emerge de bucear previamente en un lugar de encuentro, de los deseos más personales de los participantes del equipo, es decir, obviamente no de un texto, no de una idea previa, no de un concepto ni de un lugar adonde arribar (Director, entrevista).

Igualmente, consideramos los dichos:

No me interesa para nada hacer teatro pensando en un tipo de producto final o qué creo yo que interesaría al público o qué creo yo que sería el buen teatro, como esas cuestiones más especulativas, que están pensando más en un tipo de resultado. No seducen en absoluto; para mí, los proyectos surgen más de necesidades y de deseos concretos de poder transformarse a una misma con ayuda de otro y ayudarnos mutuamente a transformarnos, y de eso hacer un acontecimiento poético (Director, entrevista).

De allí condensamos los tópicos: atención sobre el producto final (h) y búsqueda sobre especulaciones de resultado (i). Mientras que en la cita posterior llegamos a los tópicos: colectivo de singularidades (j), en oposición a colectivo homogéneo (k):

[...] llegar a ver cómo se complementan los puntos de vista diferentes, heterogéneos, singulares, no perder de vista la singularidad en lo colectivo, no homogeneizar [...] Y, para ir en contra de la homogeneización, es pensar procedimientos concretos, inventar procedimientos concretos, para asegurarte que estar todos pensando lo mismo no significa perder la singularidad de mi propio punto de vista (Director, entrevista). 
Respecto de la sección siguiente, extraemos los tópicos: obra de lógicas alteradas (tema, personajes, narrativa) (l), contrario a obra de temática, personajes y narrativa convencionales (m), además de obra singular, obra poética (n), y obra convencional, algo homogéneo $(\tilde{\mathrm{n}})$ :

El teatro que yo hago, justamente, va en contra; sería como el enemigo de eso porque es como medio raro, como que no va con esas narrativas más convencionales, más convencionales en términos de que, bueno, hay una temática, hay una historia, personajes que son más o menos reconocibles. A mí me interesa más lo que altera esas lógicas (Director, entrevista).

De otro momento de la entrevista, inferimos obra como acontecimiento (o):

[...] si vamos a establecer una prioridad [entre los lenguajes] me parece que es el encuentro vivencial con, entre lo que pasa en la escena y los cuerpos en la platea, digamos. Es decir, hay algo del orden de la performance actoral que me parece que es clave al momento de generar un suceso que sea una experiencia de encuentro con esos que están ahí, es decir, con esos que vinieron a esa función (Director, entrevista).

Sobre el pasaje que se vierte a continuación, extraemos los tópicos: obra para complacer "a nadie", el colectivo creador es quien goza con la obra (p), en oposición a obra para complacer al público (q), además de presentación a público sin interés económico (r) y, su par opuesto, presentación a público por necesidad económica (s):

También porque soy consciente de una posición de privilegio; si viviera del corte de entrada, en esas circunstancias quizá piense como esos colegas que dicen eso [...] Yo sé que soy una persona privilegiada. Pero por ahí hay gente que vive del corte de entradas, entonces está bien que piense así, los apoyo. Yo, como soy una persona privilegiada que no vivo de eso, vivo de otras cosas, puedo darme el lujo de no tener que complacer a nadie con las obras (Director, entrevista).

En el último fragmento que citaremos leemos los tópicos: espectadores con capacidad de leer obras complejas (ironía) (t), en oposición a espectadores con capacidad de lectura simple de las obras (literalidad) (u), y espectadores de las salas de teatro independiente (v), así como su par opuesto, espectadores de familias, interior, populares (w): 
INVESTIGACIÓNTEATRAL

Revista de artes escénicas y performatividad

Vol. 11, Núm. 17

abril-septiembre 2020
Concepciones y especificidad del rol de la

dirección teatral

Fwala-lo Marin

[...] soy consciente de que hacer la obra en una sala va a traer tal franja de personas, de tal franja social, o de clase social, en general, y que hacerla en Laguna Larga ${ }^{12}$ va a ser muy distinto, como nos pasó en una función en Laguna Larga: la gente se paraba y se iba, así, de a montones se paraban y se iban como indignados con la escena [...] Sí, porque, bueno, no había una, no leían ironía, leían que era lo que nosotros pensábamos (Director, entrevista).

En la siguiente tabla presentamos los tópicos en función de los ejes: metodología de creación, resultado del proceso y recepción. Cada tópico de la izquierda sintetiza las concepciones que guían el hacer de la directora, sus valores y objetivos. A su vez, se presenta cada par opuesto en la columna derecha:

Tabla 2

\begin{tabular}{|c|c|c|}
\hline \multicolumn{3}{|c|}{ Tópicos en función de los ejes: metodología de creación, resultado del proceso y recepción } \\
\hline $\begin{array}{l}\text { Metodologías } \\
\text { de creación }\end{array}$ & $\begin{array}{l}\text { - Atención sobre el proceso, experimenta- } \\
\text { ción, reflexión (c) (e). } \\
\text { - El proyecto emerge de los deseos perso- } \\
\text { nales (f). } \\
\text { - Búsqueda del autoconocimiento perso- } \\
\text { nal (d). } \\
\text { - Dirección como coordinación (a). } \\
\text { - Colectivo de singularidades (j). }\end{array}$ & $\begin{array}{l}\text { - Atención sobre el producto final (h). } \\
\text { - El proyecto emerge de una idea previa, } \\
\text { de un lugar adonde arribar (g). } \\
\text { - Búsqueda sobre especulaciones de } \\
\text { resultado (i). } \\
\text { - Autoridad verticalista (b). } \\
\text { - Colectivo homogéneo (k). }\end{array}$ \\
\hline Resultado & $\begin{array}{l}\text { - Obra singular, obra poética (n). } \\
\text { - Obra como acontecimiento (o). } \\
\text { - Obra de lógicas alteradas (tema, persona- } \\
\text { jes, narrativa) (I). }\end{array}$ & $\begin{array}{l}\text { - Obra convencional, algo homogéneo (ñ). } \\
\text { - Obra como no-acontecimiento. } \\
\text { - Obra de temática, personajes y narrativa } \\
\text { convencionales }(m) \text {. }\end{array}$ \\
\hline Recepción & $\begin{array}{l}\text { - Obra para complacer "a nadie", el colecti- } \\
\text { vo creador es quien goza con la obra (p). } \\
\text { - Presentación a público sin interés econó- } \\
\text { mico (r). } \\
\text { - Espectadores con capacidad de leer } \\
\text { obras complejas (ironía) (t). } \\
\text { - Espectadores de las salas de teatro inde- } \\
\text { pendiente (v). }\end{array}$ & $\begin{array}{l}\text { - Obra para complacer al público (q). } \\
\text { - Presentación a público por necesidad } \\
\text { económica (s). } \\
\text { - Espectadores con capacidad de lectura } \\
\text { simple de las obras (literalidad) (u). } \\
\text { - Espectadores de familias, interior, popu- } \\
\text { lares (w). }\end{array}$ \\
\hline
\end{tabular}

Nota: Las columnas se plantean como oposiciones, los items de cada celda se corresponden con el par opuesto de la celda contigua.

12 Pequeña localidad de 7,400 habitantes de la provincia de Córdoba. 
En un nuevo paso de síntesis, agrupamos las nociones redundantes en enunciados más breves, relacionándolos nuevamente con su par opuesto. Este trabajo espera establecer isotopías y aproximarse a un enunciado que condense las concepciones de la persona hacedora. Entonces, a partir de estos tópicos, establecemos las siguientes isotopías:

1. Proceso vs. producto.

2. Auto-conocerse mediante la creación vs. complacer al público.

3. Singularidad vs. homogeneización.

4. Obra singular vs. obra convencional.

5. Presentación a público sin interés económico vs. presentación a público por necesidad económica.

6. Espectadores de lectura compleja vs. espectadores de lectura simple.

7. Espectadores de sala de teatro independiente vs. espectadores populares o del interior.

Tal como planteamos al principio, el objetivo es formular las concepciones que organizan el trabajo del director. Mediante el trabajo precedente de síntesis elaboramos una serie de enunciados, el siguiente paso es articularlos. Nuestro aporte es realizar una lectura del siguiente orden: con respecto a las metodologías de creación, esta propuesta de dirección privilegia el proceso de creación, la experimentación y la reflexión/pensamiento sobre la práctica escénica, donde la búsqueda de un autoconocimiento de cada miembro del grupo es el fundamento del proyecto, conformando un colectivo de singularidades, donde la dirección actúa como una coordinación. El resultado del proceso es una obra poética singular, de lógicas alteradas, cuyo objetivo es provocar un acontecimiento. La persona entrevistada se diferencia de aquellas metodologías en las que la atención está puesta en el producto final, que emergen de una idea previa y donde identifica especulaciones sobre el resultado. En esas metodologías, el grupo se homogeneiza; el director actúa como una autoridad verticalista y se complace al público por necesidad económica. Con respecto a los espectadores, se plantean aquellos que circulan por las salas de teatro independiente con capacidad de realizar lecturas complejas y los espectadores populares, las familias o del interior, que tienen una capacidad de lectura más simple de las obras. La isotopía central de este texto es crear-no crear.

\section{A modo de conclusión}

La síntesis que hemos elaborado no espera ser concluyente, sino más bien trazar un mapa provisorio de una manera de pensar, hacer y decir. La relevancia que esta concepción le da a los procesos de producción y a la experimentación permite vincularla con la noción 
de experimentalismo de Umberto Eco. El concepto implica un modo de "actuar de forma innovadora respecto a la tradición establecida", que "transgrede intencionadamente (y reestructura indirectamente) las reglas de la gramática tradicional" ("El grupo 63" 88). Eco sugiere pensar en las implicancias sociológicas del concepto: el autor experimental tendría "la voluntad de hacerse aceptar. Ofende, pero con fines podríamos decir pedagógicos, para conseguir aprobación" (ibídem).

En el caso que hemos tratado aquí fue posible constatar un ánimo de transgresión e innovación respecto a tradiciones anteriores, que abarca centralmente la ruptura con las metodologías de creación y, como consecuencia, con los productos resultantes. Las concepciones que guían esta práctica directorial están centradas en experimentar, en atravesar un proceso arriesgado y comprometido, impulsado por un fuerte espíritu democrático en la toma de decisiones y la definición de los modos de hacer. Toda la labor gravita alrededor del proceso y la metodología de creación; por ello, los aspectos receptivos de la obra quedan en segundo plano.

Existe un ánimo educativo en la noción de experimentalismo de Eco, donde el artista espera re-establecer los cánones y conseguir aprobación del público que, primeramente, no comprende la obra. En esta concepción directorial observamos que el espectador está alejado espacial y temporalmente de las prácticas centrales de la dirección. En cambio, hay un franco reconocimiento de las franjas diferenciadas de espectadores que asisten a los espectáculos en las salas de teatro independiente y a las funciones promovidas por el Estado. Otro aspecto relevante de nuestra lectura es el relativo al poder: esta concepción se distancia de las modalidades autoritarias, tanto en su forma de promover la actividad creativa en el proceso, como en la composición de la obra poética. Al mismo tiempo, valora especialmente las dinámicas grupales, ya que en el rol de coordinación espera garantizar un funcionamiento grupal sano y sustentable. El esquema de análisis que hemos propuesto para abordar la cuestión de las concepciones directoriales es un intento para conseguir escuchar, como en la música, cada instrumento en su singularidad. Cada sonido es único y en conjunto con otros, sonando o disonando, construyen la atmósfera sonora del teatro independiente argentino.

\section{Fuentes consultadas}

Aguilar, Paula, et al. "El análisis de los discursos sociales. Entre el pecado de la referencialidad y la tentación del esoterismo". I Encuentro Latinoamericano de Metodología de las Ciencias Sociales, 10 al 12 de diciembre de 2008, Universidad Nacional de La Plata. www.memoria.fahce.unlp.edu.ar/trab_eventos/ev.9535/ev.9535.pdf, consultado el 4 de abril de 2020. 
Becker, Howard. Los mundos del arte. Buenos Aires: Universidad Nacional de Quilmes, 2008.

Benveniste, Emile. “L'appareil formel de l'énonciation". Langages, vol. 5, núm. 17, 1970, pp. 12-18, www.persee.fr/doc/lgge_0458-726x_1970_num_5_17_2572, consultado el 4 de abril de 2020.

Bertrand, Denis. "Elementos de narratividad". Précis de sémiotique littéraire, traducido por Lelia Gándara. París: Nathan, 2000, pp. 181-190.

Beaulieu, Paula. "Estudio de caso. Oferta y consumo en el teatro independiente de la ciudad de Córdoba". Indicadores culturales, núm. 1, 2007, pp. 126-132. www.untref.edu. ar/documentos/indicadores2007/Estudio\%20de\%20caso\%20Oferta\%20y\%20consumo\%20en\%20el\%20teatro\%20Independiente\%20de\%20la\%20ciudad\%20de\%20 Cordoba\%20Paula\%20Beauleiu.pdf, consultado el 4 de abril de 2020.

Boenisch, Peter. Directing Scenes and Senses: The Thinking of Regie. Manchester: University Press, 2005.

Bourdieu, Pierre. Las reglas del arte. Barcelona: Anagrama, 1995.

Calsamiglia Blancafort, Helena y Amparo Tusón Valls. Las cosas del decir. Manual de análisis del discurso. Barcelona: Ariel, 1999.

Charaudeau, Patrick y Dominique Maingueneau. Diccionario de análisis del discurso. Buenos Aires: Amorrortu, 2002.

Dubatti, Jorge. "Qué políticas para las Ciencias del Arte: hacia una cartografía radicante”. AURA, vol. 2, 2014, pp. 3-28.

Dubatti, Jorge. Introducción a los estudios teatrales. Propedéutica. Buenos Aires: Atuel, 2012.

Dubatti, Jorge. "El teatro argentino en la Postdictadura (1983-2010): época de oro, destotalización y subjetividad”. Stichomythia, núm. 11-12, 2011, pp. 71-80, parnaseo.uv.es/ Ars/Stichomythia/stichomythia11-12/pdf/estudio_7.pdf, consultado el 4 de abril de 2020.

Eco, Umberto. "El grupo 63, el experimentalismo y la vanguardia”. De los espejos y otros ensayos. Barcelona: De Bolsillo, 1985.

Guber, Rosana. La etnografía. Método, campo y reflexividad. Buenos Aires: Siglo xxi, 2011. Greimas, Argildas Julius. Semántica estructural. Madrid: Gredos, 1971.

Greimas, Argildas Julius y Courtes, Joseph. Semiótica: Diccionario razonado de la teoría del lenguaje. Madrid: Gredos, 1982.

Heinich, Nathalie y Roberta Shapiro. De l'artification. Enquêtes sur le passage à l'art. París: Éditions de l'École des hautes études en sciences sociales, 2012.

Kerbrat-Orecchioni, Catherine. La enunciación. De la subjetividad en el lenguaje. Buenos Aires: Edicial, 1997. 
Marin, Fwala-lo. "Los trabajadores del arte. El caso de los directores de teatro independiente en Córdoba". Revista Pilquen, vol. 21, núm. 3, 2018, pp. 11-21, www.redalyc.org/ articulo.oa?id=347559520002, consultado el 4 de abril de 2020.

Marin, Fwala-lo. "Dirección Teatral: del mundo del pensamiento al universo de las relaciones de grupo. Reflexiones en torno los procesos de escenificación del Teatro Independiente de Córdoba". Telondefondo. Revista de teoría y crítica teatral, vol. 14, núm. 28, 2018, pp. 94-106,

Marin, Fwala-lo. "Films escénicos: teatro de préstamos y de piraterías". TOMA UNO, vol. 6, núm 6, agosto de 2018, pp. 93-107, revistas.unc.edu.ar/index.php/toma1/article/ view/20897, consultado el 4 de abril de 2020.

Marin, Fwala-lo. "De puentes y orillas: festivales como vínculo del teatro de los setenta con el teatro de postdictadura en la trayectoria de directores de Córdoba, Argentina". Latin American Theatre Review, vol. 1, núm. 53, 2019, pp. 5-24.

Marin, Fwala-lo. "La formación de directores de teatro independiente argentino: aprendizajes en una periferia de tramas eclécticas. El caso de la ciudad de Córdoba". Anagnórisis. Revista de investigación teatral, núm. 20, 2019, pp. 354-380, http://anagnorisis.es/pdfs/n20/Marin_num20(354-380).pdf, consultado el 4 de abril de 2020.

Orlandi, Eni. Análisis de discurso. Principios y procedimientos. Santiago de Chile: Lom Ediciones, 2014.

Pizarro, Cynthia. "La entrevista etnográfica como práctica discursiva: análisis de caso sobre las pistas meta-discursivas y la emergencia de categorías nativas". Revista de Antropología, vol. 57, núm. 1, 2014, pp. 461-496, www.revistas.usp.br/ra/article/ view/87770, consultado el 4 de abril de 2020.

Proust, Serge. "Portrait of the Theatre Director as an Artist". Cultural Sociology, vol. 13, 2019, pp. 338-353, https://doi.org/10.1177/1749975519837400, consultado el 4 de abril de 2020.

Rancière, Jacques. El malestar de la estética. Buenos Aires: Capital Intelectual, 2011.

Verón, Eliseo. "Diccionario de lugares no comunes". Fragmentos de un tejido. Barcelona: Gedisa, 1979, pp. 39-60.

Triquell, Ximena. "Una propuesta de análisis". Signos de infancia. Herramientas semióticas para la práctica psicopedagógica, editado por Ximena Triquell et al. Córdoba: Advocatus, 2011, pp. 79-100. 